\title{
Optimization and Experiment of Straw Back-Throwing Device of No-Tillage Drill Using Multi-Objective QPSO Algorithm
}

\author{
Hongbo Xu ${ }^{1,2}$, Zhichao Hu ${ }^{1}$, Peng Zhang ${ }^{1, *}$, Fengwei Gu ${ }^{3,4, *}$, Feng Wu ${ }^{1}$, Wanli Song ${ }^{5}$ and Chunci Wang 5 \\ 1 Nanjing Institute of Agricultural Mechanization, Ministry of Agriculture and Rural Affairs, \\ Nanjing 210014, China; xuhongbo@caas.cn (H.X.); huzhichao@caas.cn (Z.H.); wufeng@caas.cn (F.W.) \\ 2 College of Engineering, China Agricultural University, Beijing 100083, China \\ 3 Key Laboratory of Modern Agricultural Equipment, Ministry of Agriculture and Rural Affairs, \\ Nanjing 210014, China \\ 4 College of Energy and Power Engineering, Nanjing University of Aeronautics and Astronautics, \\ Nanjing 210016, China \\ 5 College of Mechanical Engineering and Automation, Northeastern University, Shenyang 110167, China; \\ songwl@me.neu.edu.cn (W.S.); penggggg@163.com (C.W.) \\ * Correspondence: zhangpeng01@caas.cn (P.Z.); gufengwei@caas.cn (F.G.)
}

Citation: $\mathrm{Xu}, \mathrm{H} . ; \mathrm{Hu}, \mathrm{Z}$.; Zhang, P.; $\mathrm{Gu}, \mathrm{F}$; $\mathrm{Wu}, \mathrm{F}$; Song, W.; Wang, C. Optimization and Experiment of Straw Back-Throwing Device of No-Tillage Drill Using Multi-Objective QPSO Algorithm. Agriculture 2021, 11, 986. https:// doi.org/10.3390/agriculture11100986

Academic Editor: José Pérez-Alonso

Received: 6 September 2021

Accepted: 7 October 2021

Published: 10 October 2021

Publisher's Note: MDPI stays neutral with regard to jurisdictional claims in published maps and institutional affiliations.

Copyright: (C) 2021 by the authors. Licensee MDPI, Basel, Switzerland. This article is an open access article distributed under the terms and conditions of the Creative Commons Attribution (CC BY) license (https:/ / creativecommons.org/licenses/by/ $4.0 /)$.
Abstract: Reducing operation energy consumption is the development demand of conservation tillage equipment. In order to solve the problems of high power consumption and the easy blockage of the no-tillage drill under full straw retention, the key parameters of the straw back-throwing device were optimized in this study. The Box-Behnken central combination test method was used to analyze the influence of the impeller rotating speed, feed quantity and cross-sectional area of the throwing pipe on the specific power consumption and throwing speed, the mathematical models of which were built with the aid of the least square method. In addition, the mathematical models were optimized by using a multi-objective quantum behaved particle swarm optimization (QPSO) with an improved target weighting coefficient. The optimization results indicated that, when the impeller rotating speed was $2287 \mathrm{r} / \mathrm{min}$, the feed quantity was $1.1 \mathrm{~kg} / \mathrm{s}$ and the cross-sectional area of the throwing pipe was $506.997 \mathrm{~cm}^{2}$, the specific power consumption and throwing speed by the models were $7528 \mathrm{~m}^{2} / \mathrm{s}^{2}$ and $11.73 \mathrm{~m} / \mathrm{s}$, respectively. The models were verified by comparing the optimization results with the measured data in the simulation filed tests, which proved that the multi-objective QPSO algorithm was feasible to optimize the working and structural parameters of the straw back-throwing device of the no-tillage drill under full straw retention. The results provide references for the parameter optimization of similar no-tillage drills under straw retention.

Keywords: no-tillage drill; straw back-throwing device; quantum behaved particle swarm optimization (QPSO); multi-objective optimization; verification test

\section{Introduction}

The sowing method of the no-tillage drill has the advantages of racing against time, high replanting index, protecting the soil ecological environment, low cost and so on [1]. Accordingly, it is adopted all over the world, especially in North America, Oceania, Europe and Asia, and is used in many crops, including corn, wheat, soybean and so on [2]. With the development of agricultural machinery, the efficiency of the no-tillage drill has become the focus of research [3]. The no-tillage drill under full straw retention can help to achieve the processes of straw chopping, straw transport, sowing, fertilization and straw mulching once and for all, which are widely used in many areas of China [4]. As an important working part of the no-tillage drill under full straw retention, the back-throwing device is of great significance to performance improvement [5]. Therefore, many scholars have studied the back-throwing device of the no-tillage drill under full straw retention [6-8].

Shinners et al. [9] studied the rotation direction of the throwing impeller and reduced the power consumption by changing the direction of the cutter. The experimental results 
showed that the specific power consumption could be reduced by $30 \%-34 \%$, which greatly improved the work efficiency, but the throwing distance of the harvester was shortened by $27 \%$. Shinners et al. [10] then went further, increasing the opening in the side of the cutting chamber to increase the air flow in the chamber and thus increase the throw distance. Chattopadhyay et al. [11] studied the effect of flail tip speed, knife rake angle and bevel angle on the conveying of chopped forage sorghum (S. bicolor) through a $90^{\circ}$ deflector elbow under laboratory conditions, which showed that the static pressure head created by the rotating flails at the blower outlet (chute inlet) increased exponentially as the flail tip speed was increased and decreased linearly when the knife rake angle was increased. Jia et al. [12] studied the motion of the throwing device of a maize no-tillage drill, established the motion micro-equation aiming at power consumption and optimized the relevant working parameters by the orthogonal polynomial regression method and variance analysis. Zhai and Wang [13] simulated the internal airflow field of the throwing device through FLUENT. The test results showed that the simulated airflow velocity at the nozzle of the straight pipe was consistent with the test, proving the accuracy of the software numerical simulation. By comparing and simulating the shell shape and blade inclination angle of the different parameters of the throwing device, it was concluded that, when the structure of the throwing device is a round shell and the blade inclination is a rearward angle, it is more beneficial to the throwing of discarded straw, and the arc radius at the exit ought not to be too large. Then, the simulation and parameter optimization of the airflow motion of the blade throwing device were carried out, and they found that the blade throwing effect was the best when tilting back $10^{\circ}$ [14]. In 2012, Zhai et al. [15] simulated the motion of discarded straw along the throwing blade, analyzed the throwing efficiency, power consumption and the movement of discarded straw in the throwing device and obtained that the optimal angle range for the movement of discarded straw in the volute was about $60^{\circ}-130^{\circ}$. However, the problems of high power consumption and congestion affect the promotion of the straw back-throwing device of the no-tillage drill under full straw retention.

To improve the power consumption and smoothness of the straw back-throwing device, it is necessary to calculate the optimal parameters that affect the working process. However, power consumption and smoothness are often mutually restrictive optimization indexes, so an appropriate multi-objective optimization algorithm is needed to solve them. Particle swarm optimization (PSO) is an evolutionary computation that simulates the predation behavior of birds, which is widely used in the engineering field $[16,17]$. On this basis, the PSO was continuously improved in order to improve the search scope and convergence speed [18].

In this paper, the equation of specific power consumption and the throwing efficiency of the back-throwing device are established to determine the reasonable structure and motion parameters. Since the relationship between the working parameters of the backthrowing device are a non-linear correlation, the least square method is used to establish the equations of the specific power consumption and the throwing speed of the back-throwing device on the relationship between the rotating speed of the throwing impeller, the feeding quantity and the cross-sectional area of the throwing pipeline. After that, an improved multi-objective quantum particle swarm optimization (IMQPSO) algorithm and improved weight coefficient are introduced to optimize the multiple parameter equations. The goal of this study is to provide references for the parameter optimization of similar no-tillage drills under straw retention.

\section{Materials and Methods}

\subsection{Back-Throwing Device of No-Tillage Drill under Full Straw Retention}

The no-tillage drill under full straw retention is mainly composed of a straw cleaning device and a no-tillage drill. The straw cleaning device, including a straw crushing device, a straw back-throwing device and a straw dispersing device, is set in front of the drill [19]. As shown in Figure 1, during the operation, the tractor provides power to drive the operation 
of the straw crushing device and the straw back-throwing device. After the residual straw in the field is picked and crushed by the straw crushing device, the straw is transported and lifted by the straw back-throwing device, and it is evenly thrown back under the action of the dispersing device. Thus, the no-tillage drill is planting in the area without any residual straw, which can significantly improve the working smoothness and sowing quality.

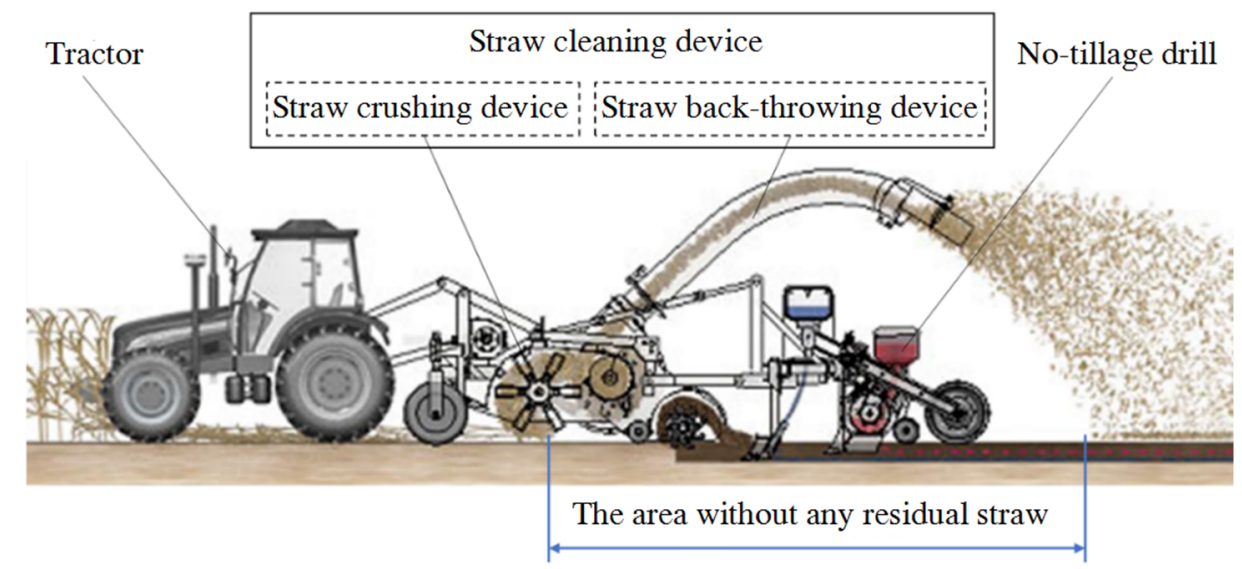

Figure 1. Operation principle of no-tillage drill under full straw retention.

The straw back-throwing device is mainly composed of throwing impeller and throwing pipeline (Figure 2). The crushed straw is thrown along the pipeline under the action of rotation of the impeller. The parameters of the back-throwing device affect the throwing smoothness and the power consumption of the device. Realizing smooth throwing with the lowest power consumption is the design goal of the back-throwing device.

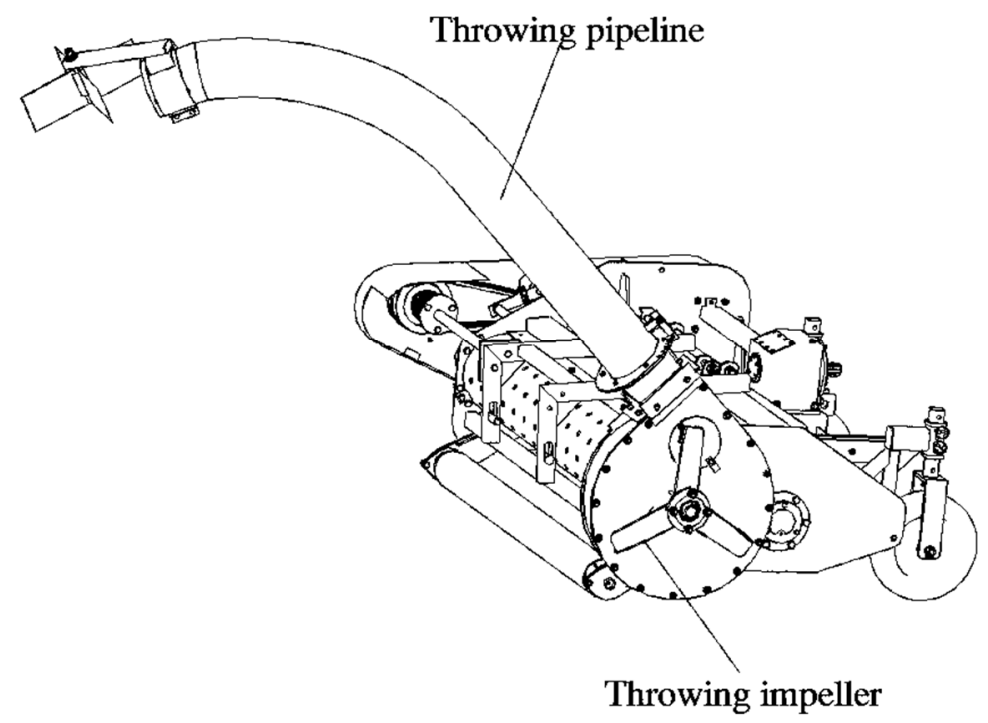

Figure 2. The structure of straw back-throwing device.

\subsection{Performance Testing of Throwing Device}

Specific power consumption reflects the power consumption per unit mass of straw, while throwing speed reflects the operation smoothness of straw back-throwing device. Thus, the specific power consumption and throwing speed under different working parameters of the straw back-throwing device were determined as evaluation indexes of the straw back-throwing device in the study. The installation mode of the test device is shown in Figure 3. A rotational speed and torque sensor was installed between the power output shaft of the tractor and the power input shaft of the transmission box of the straw cleaning 
device. A high-speed camera acquisition system was placed on the side of the forward path of the straw back-throwing device and focused on the outlet of the throwing pipeline.

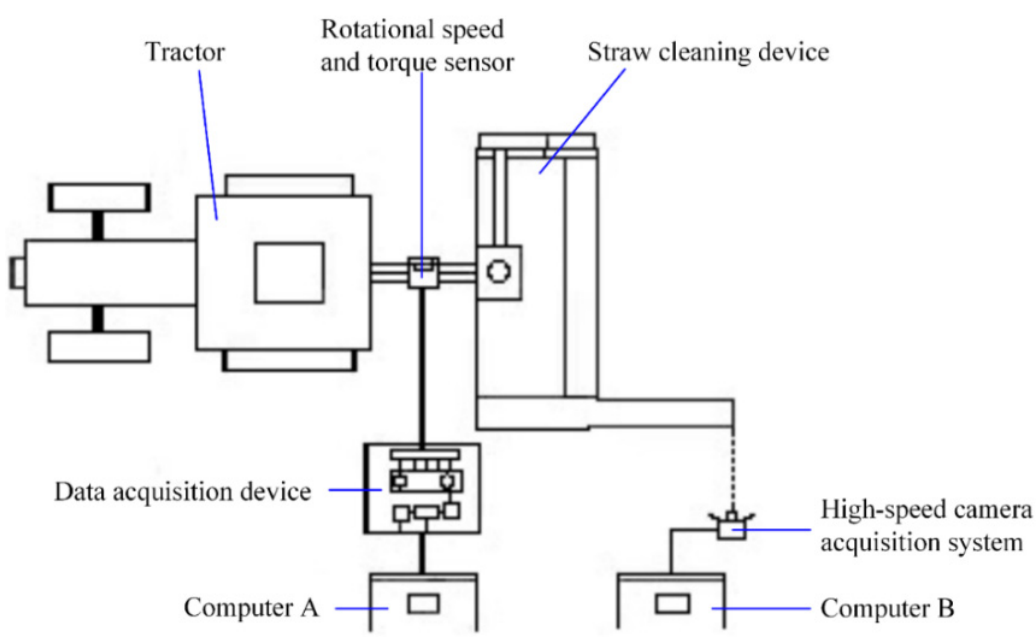

Figure 3. The installation method of testing device.

The experimental site was at the east area of Nanjing Institute of Agricultural Mechanization, Ministry of Agriculture and Rural Affairs (Nanjing, China). The straw was the chopped part of rice harvested by Jiangsu Academy of Agricultural Sciences (Jiangsu, China). The length of discarded straw after crushing was less than $120 \mathrm{~mm}$, and the moisture content of straw was $65 \%$. The simulated field was manually laid with a laying density of $2 \mathrm{~kg} / \mathrm{m}^{2}$ and a width of $2.2 \mathrm{~m}$. The main instruments used in the test: powered tractor, measuring tape, electronic balance, the SL06 rotational speed and torque sensor (Beijing Sanjing United Technology Co., LTD., Beijing, China) and HiSpec5 high-speed camera acquisition system (FASTEC IMAGING Co., LTD., San Diego, CA, USA) with a resolution of $1376 \times 1132$ pixels, sampling frame frequency of 200 FPS, exposure time of $4998 \mu \mathrm{s})$ were used to measure specific power consumption and throwing speed.

Orthogonal rotational quadratic combination test with three factors and three levels was made to evaluate the combined influence of the factors on the test index value. Based on previous single-factor test results and practical operability, the throwing effect is well within the rotating speed of throwing impeller of $1800-2700 \mathrm{r} \cdot \mathrm{min}^{-1}$. According to the conventional operation efficiency of machines and tools and the amount of straw in the field, the variation range of feeding amount is controlled at $1.1-1.7 \mathrm{~kg} \cdot \mathrm{s}^{-1}$. When the cross-sectional area of the throwing pipeline is $207-507 \mathrm{~cm}^{2}$, the structure of throwing pipeline is reasonable and not easy to jam. The factors and levels of the test are shown in Table 1.

Table 1. Factors and levels of orthogonal rotational quadratic combination test.

\begin{tabular}{|c|c|c|c|}
\hline Level & $\begin{array}{l}\text { Rotate Speed of Throwing } \\
\text { Impeller }\left(r \cdot \min ^{-1}\right)\end{array}$ & $\begin{array}{l}\text { Feeding Quantity } \\
\left(\mathrm{kg} \cdot \mathrm{s}^{-1}\right)\end{array}$ & $\begin{array}{l}\text { Sectional Area of Throwing } \\
\text { Pipeline }\left(\mathrm{cm}^{2}\right)\end{array}$ \\
\hline-1 & 1800 & 1.1 & 207 \\
\hline 0 & 2250 & 1.4 & 357 \\
\hline 1 & 2700 & 1.7 & 507 \\
\hline
\end{tabular}

During the test, the power consumption $P_{j}$ of the straw cleaning device under different working parameters with the rotational speed and torque sensor was measured, and the straw throwing image at the outlet of the throwing pipeline with the high-speed camera acquisition system was recorded. Then, the belt drive between the straw crushing device and the straw back-throwing device was removed, and then the above tests were repeated. 
The power consumption $P_{q}$ was recorded in the meantime. The specific power consumption of the straw back-throwing device is

$$
P_{s}=\frac{P_{j}-P_{q}}{Q}
$$

while $P_{S}$ is the specific power consumption of the straw back-throwing device, $\mathrm{m}^{2} / \mathrm{s}^{2} ; P_{j}$ is the power consumption of the straw cleaning device, $\mathrm{W} ; P_{q}$ is the power consumption of the straw cleaning device without back-throwing device, $\mathrm{W} ; Q$ is the feeding quantity, $\mathrm{kg} / \mathrm{s}$. Straw throwing images under different working conditions were recorded by the highspeed camera acquisition system, and then the straw throwing speed $V_{p}$ was obtained by the video processing software (Proanalyst Professional 2D, Xcitex Inc., Woburn, MA, USA).

\subsection{Improved Multi-Objective Particle Swarm Optimization Algorithm}

The multi-objective quantum particle swarm optimization (MQPSO) algorithm is an improvement of ordinary quantum particle swarm optimization (QPSO) algorithm [20]. In this paper, the dynamic weighting method (DWM) is used to improve the MQPSO algorithm. The DWM can be used to solve the problems of low efficiency, multi-objective optimization with convex shape and difficulty in ensuring the accuracy of the optimal value. By dynamically changing the value of the weight coefficient, the optimization results can be prevented from being incorrect due to the constant weight coefficient. When the problem of multi-objective optimization is two-objective, its weight coefficient can usually be changed according to Equation (2)

$$
\omega_{1}=m-(m-n) \times \frac{t}{\text { MaxTimes }} \omega_{2}=1-\omega_{1}
$$

where $t$ is the number of optimized iterations; $m$ and $n$ are the adjustment coefficients. In general, they are constants, and the specific values are determined according to the actual situation. MaxTimes is the maximum number of iterations; $\omega_{1}, \omega_{2}$ are the inertia weights of the two targets, respectively.

The scholar Shi.Y [21] found that a small value of inertia weight was beneficial to local search, while a large value of inertia weight was beneficial to global search. Based on the previous conclusion, Shi.Y proposed the linear decreasing inertia weight, as shown in Equation (2), with the purpose of balancing the local search capability and the global search capability so as to better solve the multi-objective optimization problem. According to the traditional experience, the performance of the algorithm is best when the inertia weight of $m$ is 0.9 and $n$ is 0.4 . The inertia weight decreases linearly from 0.9 to 0.4 . In the early stage, the higher the inertia weight is, the better the global search ability of the algorithm will be. With the progress of iteration, the lower the inertia weight is, the stronger the local search capability of the algorithm will be.

The inertia weight is improved to change linear decline into parabolic decline so that the global search in the early stage is more comprehensive and the local search in the later stage is faster. The inertia weight after modification is shown as follows:

$$
\omega_{1}=m-(m-n) \times\left(\frac{t}{\text { MaxTimes }}\right)^{3} \omega_{2}=1-\omega_{1}
$$

Figure 4 shows the dynamic change of $\omega$ before and after the improvement. 


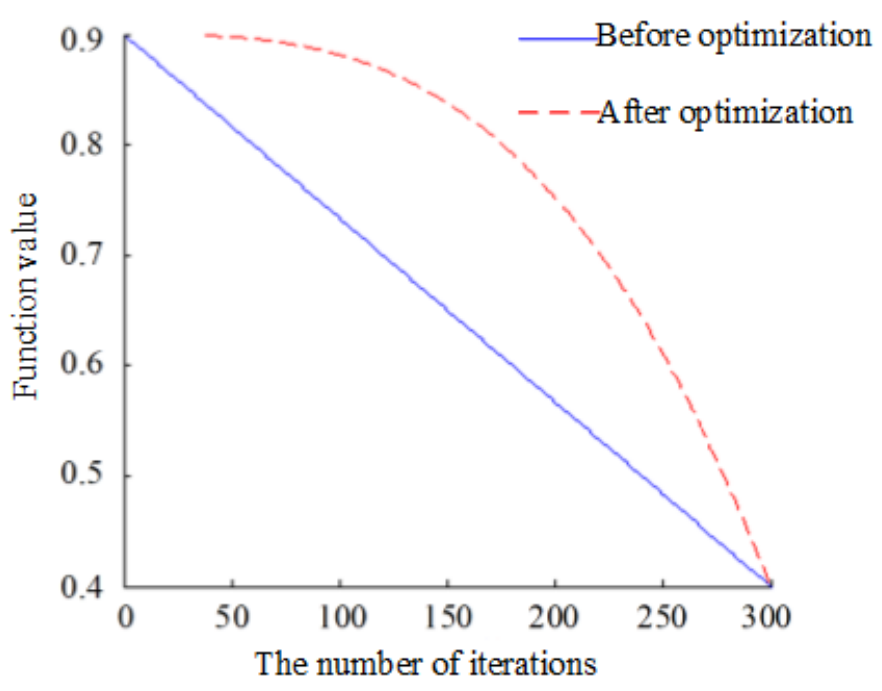

Figure 4. The change of two inertia weight.

The following is an analysis of the performance of the two $\omega$ changing algorithms, and the following functions are selected for testing:

$$
f(x)=\frac{\sin \sqrt{\left(x^{2}+y^{2}\right)}}{\sqrt{\left(x^{2}+y^{2}\right)}}+e^{\frac{\cos 2 \pi x+\cos 2 \pi y}{2}}-2.71289
$$

Figure 5 shows a graph of the function to test the performance of the algorithm. It shows that the function has a lot of local maximum points. This function is used to test the performance of inertia weight to check whether the function falls into local maximum. The extremum gets the maximum near $(0,0)$ coordinate.

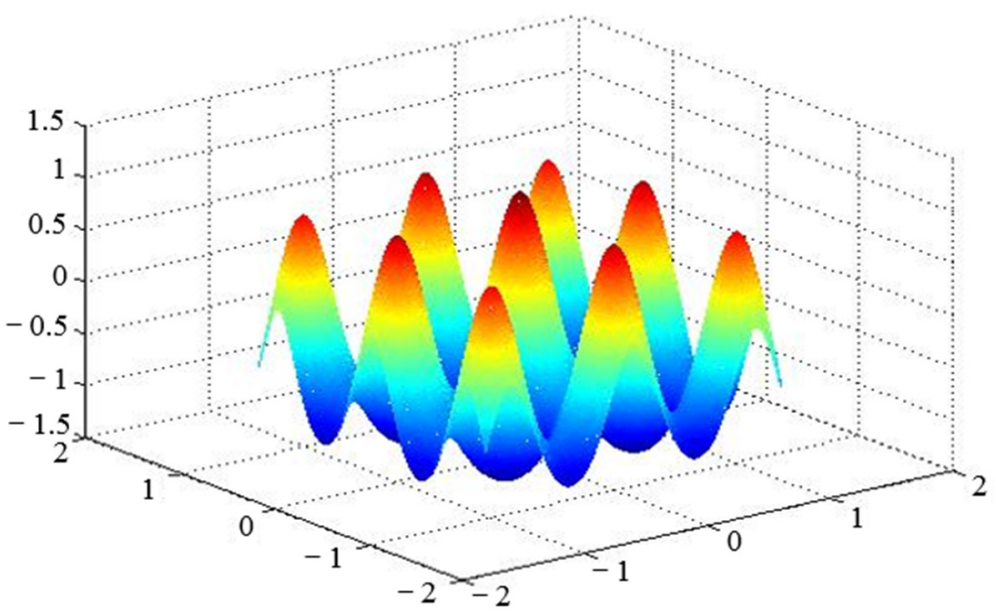

Figure 5. Function to test the algorithm performance.

The algorithm parameter is set to population size of 20 and evolution of 300 generations. The experiment is set up to run for 100 times, and the average of 100 times is taken as the final result. The two inertia weights are solved, and the average value, failure times and near-optimal times of the solutions are compared to analyze the convergence accuracy, convergence speed and other performances.

Table 2 shows that the improved inertia weight searches the same optimal solution, but the average value is closer to the optimal solution, and the times fall into suboptimal solution significantly less than before the improvement. The improved inertia weight function keeps a large value of the inertia weight $\omega$ at the beginning of the iteration, which can increase the global search time in the early stage and quickly enter the local search 
in the later stage so as to improve the search efficiency (Figure 6). After the iteration to 150 generations, the global optimum is achieved, the convergence rate is faster than before the improvement and the solution accuracy is higher.

Table 2. Performance comparison of different inertia weights.

\begin{tabular}{|c|c|c|c|c|}
\hline & $\begin{array}{c}\text { The Optimal } \\
\text { Solution }\end{array}$ & The Average Value & $\begin{array}{c}\text { The Number of Times to } \\
\text { Get into a Suboptimal } \\
\text { Solution }\end{array}$ & $\begin{array}{c}\text { The Number of Times to } \\
\text { Approach the Optimal } \\
\text { Solution }\end{array}$ \\
\hline$\omega_{1}=m-(m-n) \times \frac{t}{\text { MaxTimes }}$ & 1.0054 & 0.9801 & 16 & 84 \\
\hline$\omega_{1}=m-(m-n) \times\left(\frac{t}{\text { MaxTimes }}\right)^{3}$ & 1.0054 & 1.0052 & 0 & 100 \\
\hline
\end{tabular}

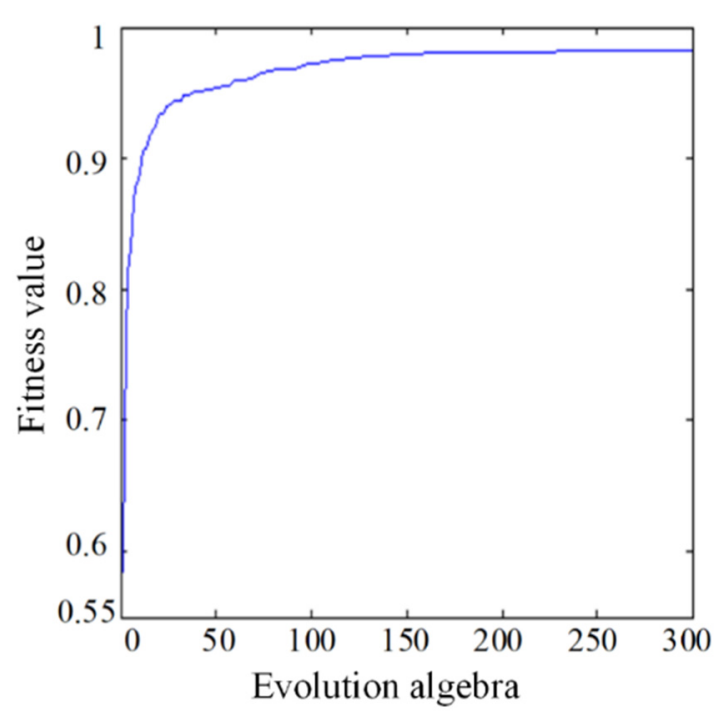

(a)

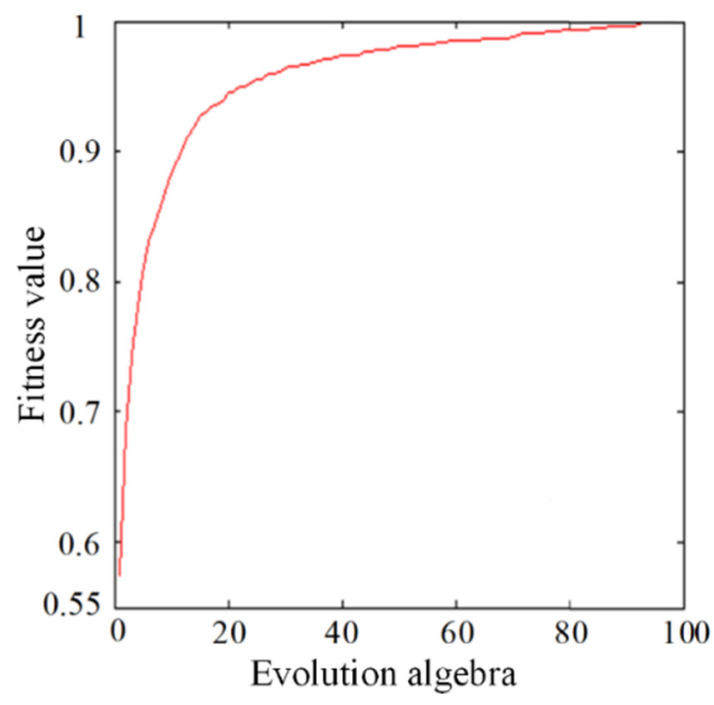

(b)

Figure 6. The convergence curve of the average value of the function before and after the improvement of inertia weight: (a) before improving; (b) after improving.

Assuming that the optimization function of a two-objective is $F(X)=\left(f_{1}(X), f_{2}(X)\right)^{\mathrm{T}}$, the purpose is to find the minimum value of $F(X)$, then the main steps of optimization using IMQPSO algorithm are as follows:

(1) Initialize the particle swarm in which $\mathrm{n}$ particles are generated at random and are expressed in vector form. The position of the least adaptable of all particles is set as the initial position.

(2) The average optimal position value of the whole particle swarm can be obtained by using the Equation (5).

$$
m_{\text {best }}=\operatorname{sum}\left(p_{\text {best }}\right) / n
$$

(3) According to Equation (3), the weight coefficient of each objective function is obtained;

(4) The random points $P P_{i j}$ and position of each particle are obtained according to the position update formula of QPSO algorithm.

(5) Calculate the $p_{\text {best }}$ value of the new position of each particle;

(6) Find the global optimal position $g_{b e s t}$;

(7) Repeat steps Equations (2)-(6) above until the algorithm can meet the initial termination conditions. Finally, a set of Pareto optimal solution sets is given. 


\section{Results}

\subsection{The Equation of Response Surface}

Before using the least square method to fit the function, it is necessary to process the experimental data with the help of Design-Expert software and make the equation fit closer to the actual value by analyzing the correlation of the parameters [22-24].

The variance analysis results of the throwing velocity [25] showed that the influencing factors were mainly the impeller speed and the cross-sectional area. The impeller speed and pipe cross-sectional area were extracted from the Box-Behnken test design table, and zero level was selected for the feeding quantity to obtain the relation table of the throwing speed on the impeller speed and the pipe cross-sectional area, as shown in Table 3.

Table 3. The relationship among the throwing speed, the rotate speed of throwing impeller and the sectional area of throwing pipeline.

\begin{tabular}{ccc}
\hline Impeller Speed $(\mathbf{r} / \mathbf{m i n})$ & Cross-Sectional Area $\left(\mathbf{c m}^{2}\right)$ & Throwing Speed $\mathbf{( m / s )}$ \\
\hline 2700 & 207 & 13.1 \\
2700 & 507 & 14.8 \\
1800 & 507 & 9.8 \\
2250 & 357 & 11.2 \\
1800 & 207 & 8.2 \\
\hline
\end{tabular}

Similarly, the relation table of the specific power consumption with the impeller speed, feeding quantity and cross-sectional area of the throwing pipeline is shown in Table 4.

Table 4. The relationship among the specific power consumption, the rotate speed of throwing impeller, feeding quantity and sectional area of throwing pipeline.

\begin{tabular}{|c|c|c|c|}
\hline $\begin{array}{l}\text { Impeller Speed } \\
(\mathrm{r} / \mathrm{min})\end{array}$ & $\begin{array}{l}\text { Feeding Quantity } \\
\text { (kg/s) }\end{array}$ & $\begin{array}{c}\text { Cross-Sectional Area } \\
\left(\mathrm{cm}^{2}\right)\end{array}$ & $\begin{array}{c}\text { Specific Power } \\
\text { Consumption }\left(\mathrm{m}^{2} / \mathrm{s}^{2}\right)\end{array}$ \\
\hline 2700 & 1.4 & 207 & 16,930 \\
\hline 2250 & 1.4 & 357 & 6440 \\
\hline 2700 & 1.4 & 507 & 20,540 \\
\hline 1800 & 1.4 & 507 & 5340 \\
\hline 2250 & 1.1 & 207 & 7120 \\
\hline 2700 & 1.1 & 357 & 18,090 \\
\hline 2700 & 1.7 & 357 & 19,210 \\
\hline 1800 & 1.7 & 357 & 6060 \\
\hline 1800 & 1.1 & 357 & 5300 \\
\hline 2250 & 1.7 & 507 & 9900 \\
\hline 1800 & 1.4 & 207 & 5140 \\
\hline 2250 & 1.1 & 507 & 7160 \\
\hline 2250 & 1.7 & 207 & 7250 \\
\hline
\end{tabular}

The variance analysis was used to eliminate the factors that have less influence on the specific power consumption and throwing speed. The response surface equation of the specific power consumption and throwing speed is as follows:

$$
\begin{gathered}
Y_{1}=100.927-0.0897 X_{1}-2.776 X_{2}-0.0582 X_{3}+1.263 \times 10^{-5} X_{1} X_{3} \\
+0.0145 X_{2} X_{3}+2.2269 \times 10^{-5} X_{1}^{2}+8.941 \times 10^{-3} X_{2}^{2}+1.98 \times 10^{-5} X_{3}^{2} \\
Y_{2}=-2.9185+5.28 \times 10^{-3} X_{1}+5.28 \times 10^{-3} X_{3}
\end{gathered}
$$

where $Y_{1}$ is the specific power consumption and $Y_{2}$ is the throwing speed.

\subsection{The Detection of Regression Model}

The reliability of the model was verified by the analysis of the predicted and actual test values and the residual analysis. Figure 7 shows the analysis diagram of the predicted 
value and the actual test value using the software of Design-Expert V8.0.6.1 (Stat-Ease Inc., Minneapolis, MN, USA). The proximity of the predicted value and the actual test value reflected the reliability of the equation.
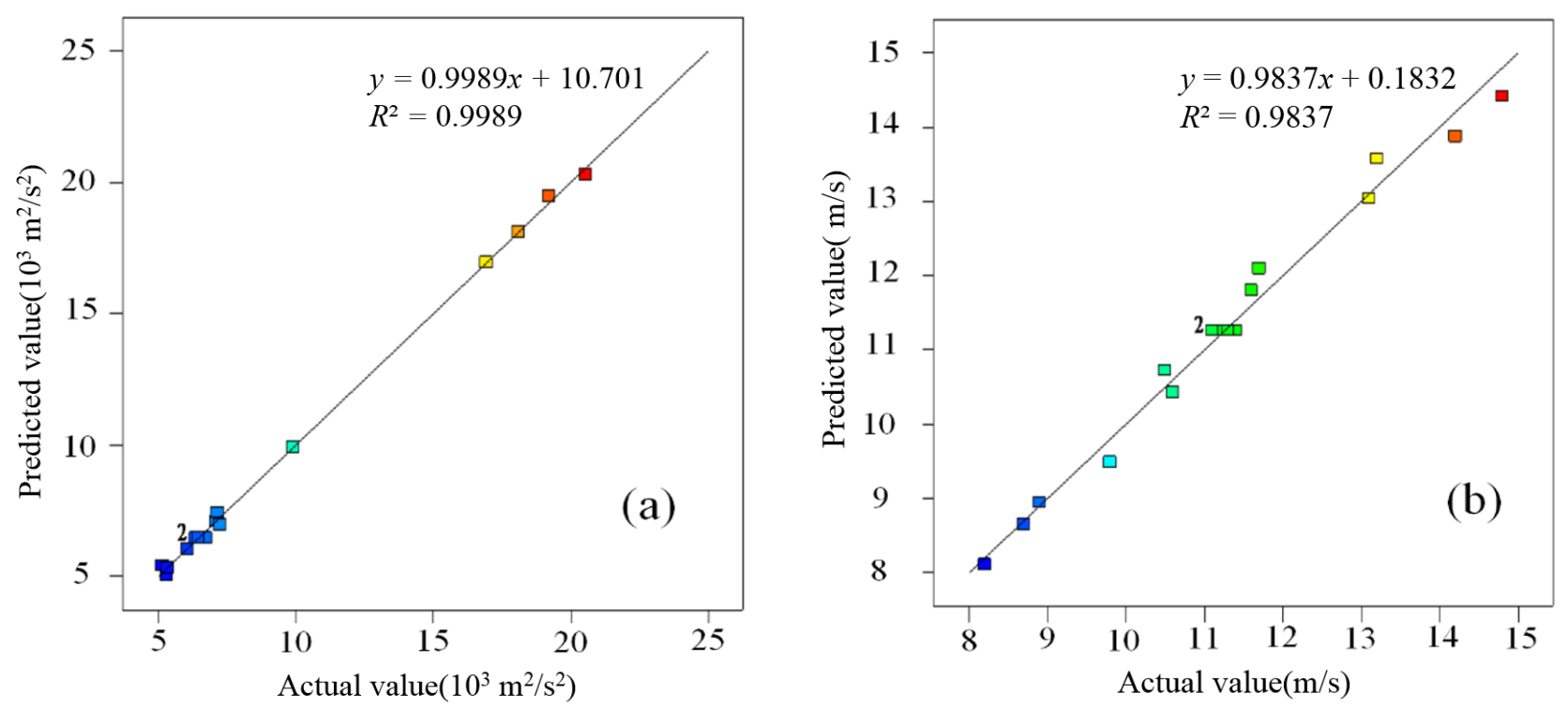

Figure 7. Analysis of predicted and actual values of specific power consumption and throwing speed: (a) Specific power consumption; (b) Throwing speed.

Figure 8 is the residual analysis diagram of the regression equation for the specific power consumption and throwing speed; the ordinate was the normal distribution probability of the residual, and the abscissa was the value of the residual after standardization. It can be seen that the residual is basically on a straight line, which demonstrates that the error of the regression equation of specific power consumption and throwing speed was normally distributed; that is, the fitted equation satisfied the requirements of the least square regression analysis method.
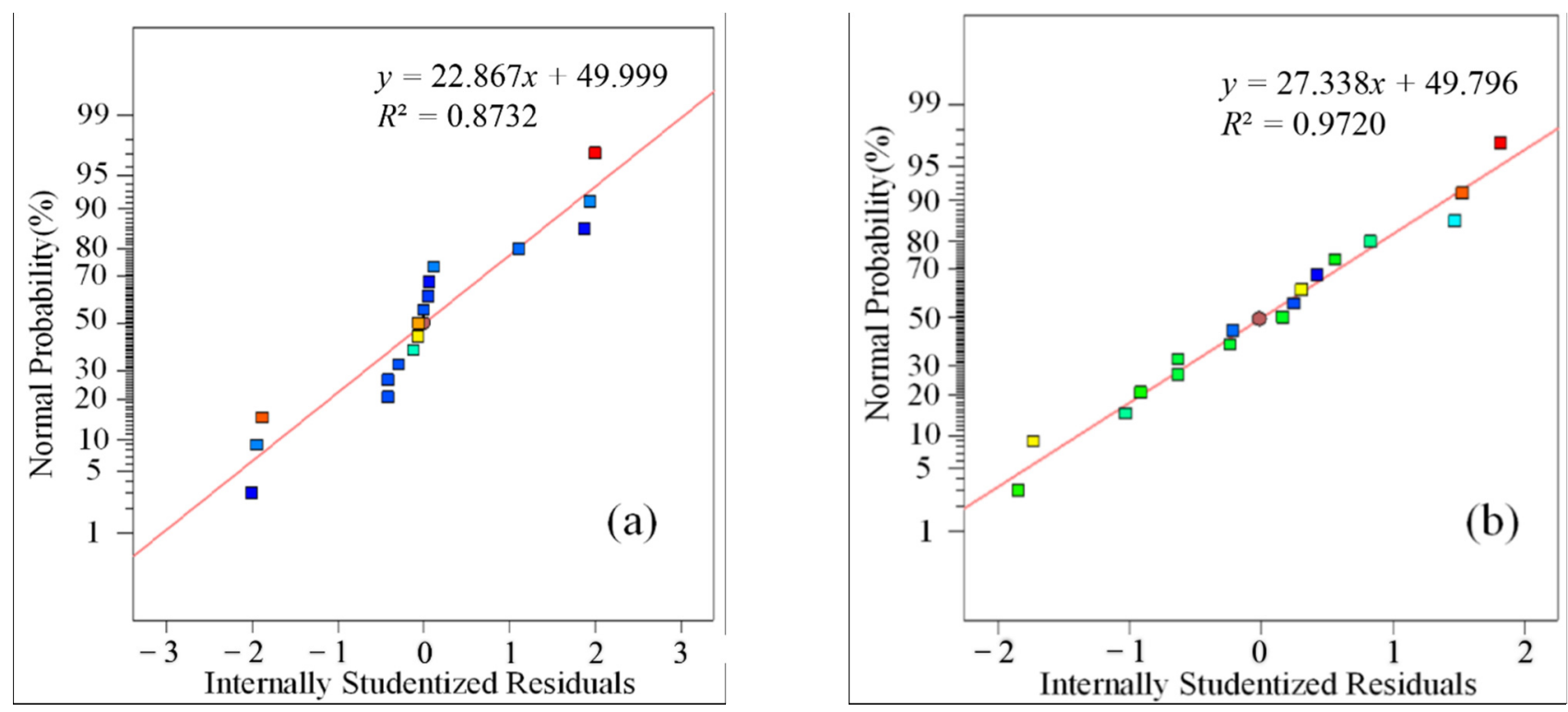

Figure 8. The residual analysis of specific power consumption and throwing speed: (a) Specific power consumption; (b) Throwing speed. 


\subsection{Parameters Optimization of Back-Throwing Device Based on IMQPSO Algorithm}

The improved algorithm is used to optimize the function so that both objective functions are minimized. According to Equations (6) and (7), two objective optimization problems are expressed as:

$$
\begin{gathered}
f_{1}=100.927-0.0897 A-2.776 B-0.582 C+1.263 \times 10^{-5} A C+0.0145 B C \\
+2.2269 \times 10^{-5} A^{2}+8.941 \times 10^{-3} B^{2}+1.98 \times 10^{-5} C^{2} \\
f_{2}=\frac{10}{Y_{2}}=\frac{10}{2.9185+5.28 \times 10^{-3} \times A+5.28 \times 10^{-3} C}
\end{gathered}
$$

Constraint conditions:

$$
\begin{aligned}
1800 & \leq A \leq 2700 \\
1.1 & \leq B \leq 1.7 \\
207 & \leq C \leq 507
\end{aligned}
$$

where $A$ is the speed of the throwing impeller ( $/ \mathrm{min}) ; B$ is the feed quantity $(\mathrm{kg} / \mathrm{s}) ; C$ is the sectional area of the throw pipe $\left(\mathrm{cm}^{2}\right)$.

Function $f_{1}$ is the equation of the specific power consumption of the back-throwing device, and function $f_{2}$ is the equation of the throwing speed. The goal is to find one or more sets of solutions that minimize functions $f_{1}$ and $f_{2}$ at the same time. It is almost impossible for $f_{1}$ and $f_{2}$ to meet the minimum value at the same time, so our goal is to find a set of Pareto optimal solutions, making one target value as small as possible while not making another target value increase. The IMQPSO is used to optimize the above two objective functions, and the specific steps are carried out according to Figure 9.

When the flow chart of the algorithm is determined, it is necessary to program the MATLAB algorithm, of which the specific set values of the main parameters are shown in Table 5.

Table 5. The main parameters of IMQPSO.

\begin{tabular}{cc}
\hline Parameter & Parameter Value \\
\hline Number of Particle Swarm $n$ & 50 \\
Maximum Number of Iterations MaxDT & 100 \\
Maximum Weight Coefficient $\omega_{\max }$ & 1 \\
Dimension of the Independent Variable & 3 \\
\hline
\end{tabular}

Figure 10 is the Pareto curve of all the optimal solutions obtained through the calculation results drawn by the software of MATLAB 2016b (MathWorks Inc., Natick, MA, USA). The figure is basically a curve, very smooth, and all the particles involved in the operation are at the edge of the Pareto or at least close to the edge, so all the solutions obtained are the solutions that meet the optimization requirements. It shows that the improved QPSO algorithm can solve the optimization problem of the working parameters of the back-throwing device of a no-tillage drill under full straw retention. 


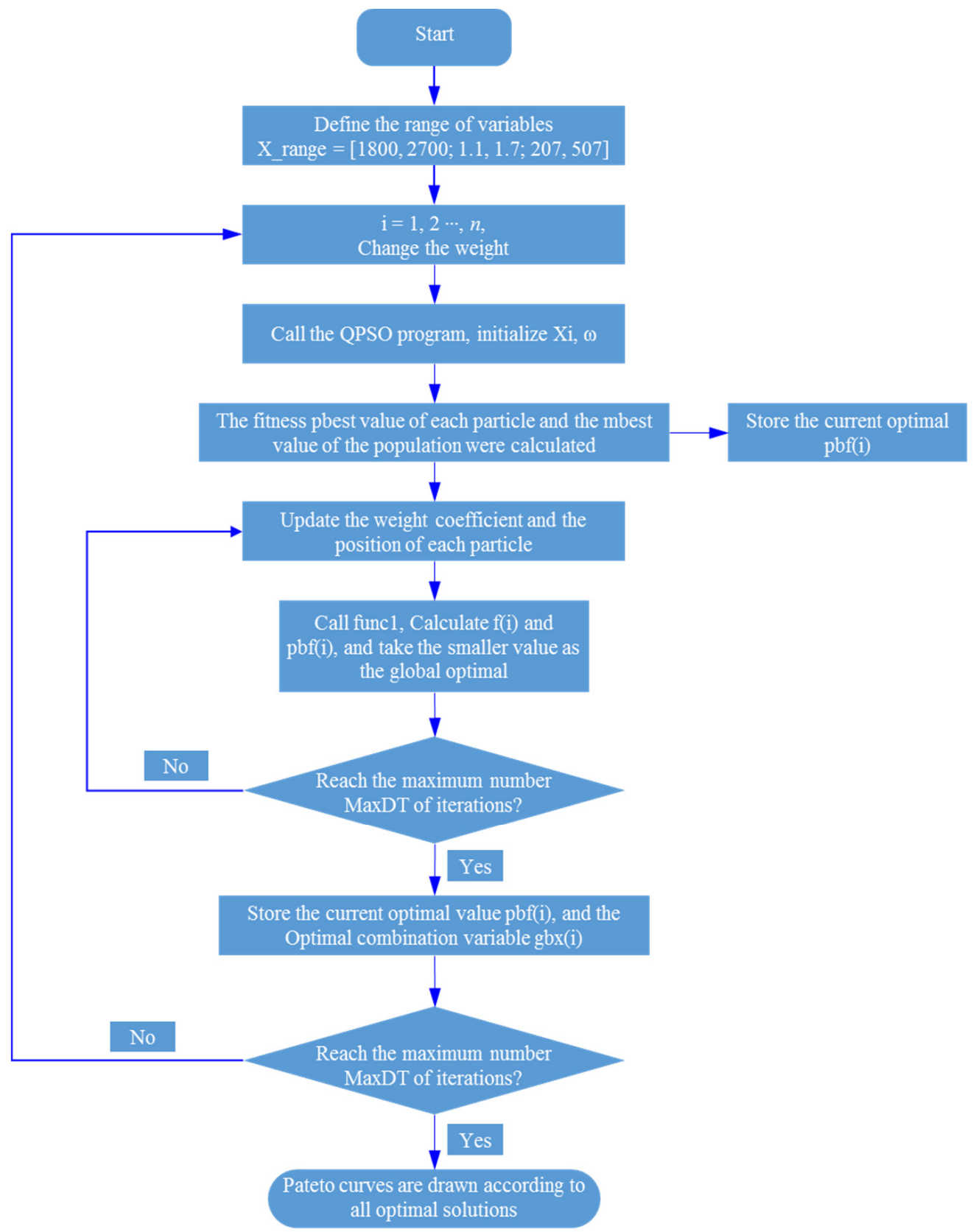

Figure 9. Flow chart of IMQPSO algorithm.

In Figure 10, all the points on the Pareto curve are the optimal solutions of the specific power consumption and the throwing speed parameters of the back-throwing device, indicating that they are mutually restricted. In practice, it is necessary to decide whether to choose a small, specific power consumption or a large throwing speed according to the demand. In this paper, it is required to achieve as little power consumption as possible and as much throwing speed as possible, so the center point on the Pareto frontier is selected as the best solution, which is $(7528,11.73)$. The values of the operating parameters of the back-throwing device corresponding to the optimal solution, and the results of the optimal solution are shown in Table 6. 


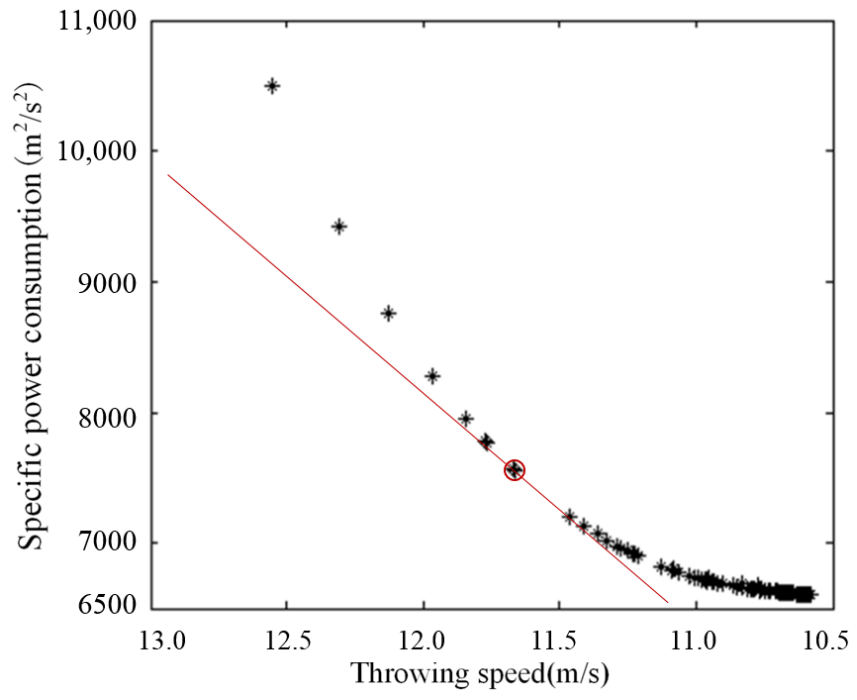

Figure 10. The Pareto graph of specific power consumption and throwing speed.

Table 6. Optimization of process parameters and corresponding optimal results.

\begin{tabular}{ccccc}
\hline $\begin{array}{c}\text { Impeller Speed } \\
(\mathbf{r} / \mathbf{m i n})\end{array}$ & $\begin{array}{c}\text { Feeding } \\
\text { Quantity }(\mathbf{k g} / \mathbf{s})\end{array}$ & $\begin{array}{c}\text { Cross-Sectional } \\
\text { Area }\left(\mathbf{c m}^{\mathbf{2}}\right)\end{array}$ & $\begin{array}{c}\text { Specific Power } \\
\text { Consumption } \\
\left(\mathbf{m}^{2} / \mathbf{s}^{2}\right)\end{array}$ & $\begin{array}{c}\text { Throwing } \\
\text { Speed }(\mathbf{m} / \mathbf{s})\end{array}$ \\
\hline 2287 & 1.1 & 506.997 & 7528 & 11.73 \\
\hline
\end{tabular}

\subsection{Verification Test}

In order to verify the accuracy of the prediction model, the above parameters were used to conduct three repeated tests in the east area of Nanjing Institute of Agricultural Mechanization, Ministry of Agriculture and Rural Affairs (considering the feasibility of the test, the throwing impeller speed was set to $2270 \mathrm{r} / \mathrm{min}$, the feeding quantity was $1.1 \mathrm{~kg} / \mathrm{s}$ and the cross-sectional area of the throwing pipe was $507 \mathrm{~cm}^{2}$ ), and the average value of the three tests was taken as the test verification value. The test scenario is shown in Figure 11.

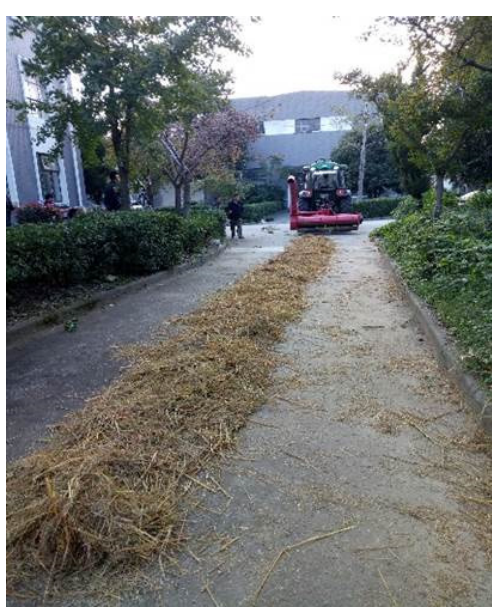

(a)

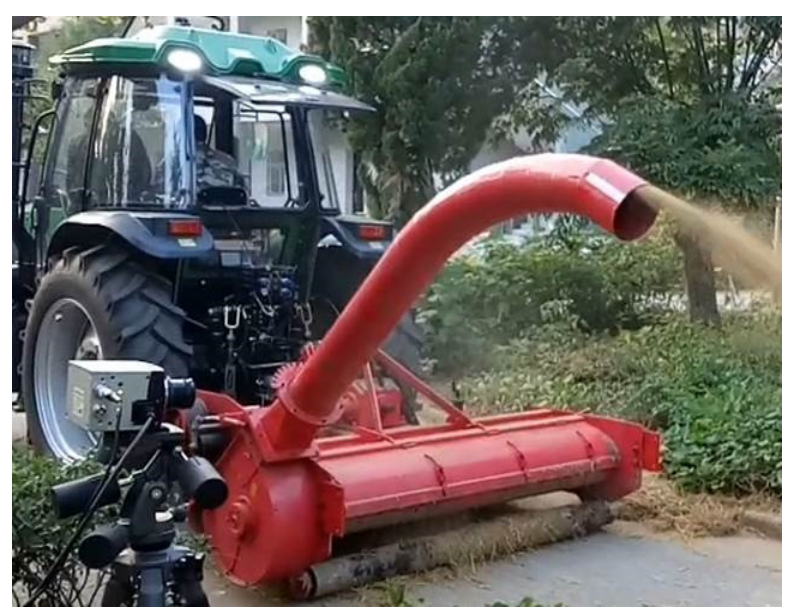

(b)

Figure 11. The scenario of verification test: (a) the simulative residual straw; (b) the operation process of back-throwing device. 
Through the above method, the specific power consumption and throwing speed of the back-throwing device were measured, and the experimental results were compared with the optimized results, as shown in the Table 7.

Table 7. The relationship among the specific power consumption, the rotate speed of throwing impeller, feeding quantity and sectional area of throwing pipeline.

\begin{tabular}{cccc}
\hline & $\begin{array}{c}\text { The } \\
\text { Optimization } \\
\text { Results }\end{array}$ & $\begin{array}{c}\text { The } \\
\text { Experimental } \\
\text { Results }\end{array}$ & Error (\%) \\
\hline Specific Power Consumption $\left(\mathrm{m}^{2} / \mathrm{s}^{2}\right)$ & 7528 & 7180 & 4.8 \\
Throwing Speed $(\mathrm{m} / \mathrm{s})$ & 11.73 & 11.60 & 1.1 \\
\hline
\end{tabular}

Compared with the results in Table 7, the optimal solution of the specific power consumption and throwing speed of the back-throwing device obtained by the IMQPSO algorithm was very close to the experimental results, and the error of the specific power consumption and throwing speed was less than $5 \%$. It could also be proved that the IMQPSO algorithm was effective, indicating that the improved optimization algorithm was feasible to optimize the back-throwing device.

\section{Discussion}

The results suggested that the specific power consumption increased with the increase of the speed of the throwing impeller and the cross-sectional area of the throwing pipe. The main reasons are as follows: when the speed of the throwing impeller increased, the energy consumed to provide its own operation and promote the movement of air flow and straw increased exponentially; therefore, the specific power consumption also increased exponentially. This result coincided with what Zhai et al. found in 2013 [26]. When the cross-sectional area of the throwing pipe is larger, the static pressure of the throwing impeller is smaller and the dynamic pressure of the throwing impeller is higher. Therefore, the air flow velocity increased the specific power consumption.

Considering the controllability of the index levels and test costs, we only conducted an artificial simulation test. Nevertheless, the existing experimental data were adequate to guide the parameter optimization of the straw back-throwing device. In the future, we will conduct a field test to further study the factors affecting the power consumption of the no-tillage drill.

By improving the particle swarm optimization algorithm, this paper theoretically optimized the structure and working parameters of the straw back-throwing device and also carried out some experimental verification. The power consumption of the improved device was reduced with the optimization of the working parameters. However, from the theoretical aspect, the optimization analysis of large agricultural machinery is still in an initial stage [27]. The improved particle swarm optimization algorithm in this paper only added quantum mechanics on the traditional basis so that it can accelerate convergence and avoid falling into local optimization, and dynamic weighting was added to make it meet the two objective functions. Furthermore, other algorithms can also be added for fusion to make the optimization method universal.

\section{Conclusions}

This article mainly studied the straw back-throwing device of a no-tillage drill under full straw retention through performance testing and established the equation of the operating parameters of the back-throwing device by using the test data. The quantum mechanics and weighting function were added to the traditional particle swarm optimization algorithm in order to find the combination of operating parameters with the minimum specific power consumption and the maximum throwing speed. By calculating, the most suitable solution was selected: the rotating speed of the throwing impeller was $2287 \mathrm{rad} / \mathrm{min}$, the feeding quantity was $1.1 \mathrm{~kg} / \mathrm{s}$ and the cross-sectional area of the throwing pipe was 
$506.997 \mathrm{~cm}^{2}$. The specific power consumption of $7528 \mathrm{~m}^{2} / \mathrm{s}^{2}$ and the throwing speed of $11.73 \mathrm{~m} / \mathrm{s}$ were obtained, which proves that the IMQPSO algorithm is feasible to optimize the back-throwing device. After verification, the test results were compared with the theoretical values, which showed that the IMQPSO algorithm was effective, indicating that the improved optimization algorithm was feasible to optimize the back-throwing device. This article provides a solution for the improvement of large agricultural machinery and also applies to other parts of the machine.

Author Contributions: Conceptualization, H.X. and Z.H.; methodology, W.S. and Z.H.; software, C.W.; validation, P.Z., H.X. and F.G.; formal analysis, W.S.; investigation, C.W.; data curation, H.X.; F.W.; writing-original draft preparation, H.X.; writing—review and editing, P.Z.; supervision, P.Z. and F.G. All authors have read and agreed to the published version of the manuscript.

Funding: This research was funded by Jiangsu Agricultural Science and Technology Innovation Fund (Grant No. CX (20)3066) and the Natural Science Foundation of Jiangsu Province (Grant No.BK20190140).

Institutional Review Board Statement: Not applicable.

Informed Consent Statement: Not applicable.

Data Availability Statement: The datasets used and/or analyzed during the current study are available from the corresponding author on reasonable request.

Conflicts of Interest: The authors declare that they have no competing interests.

\section{References}

1. Zhang, X.R.; He, J.; Li, H.W.; Li, W.Y.; Li, H. Design and experiment on the driving disc of anti-blocking unit for no-tillage planter. Trans. CSAM 2009, 25, 117-121.

2. Barr, J.; Desbiolles, J.M.; Fielke, J.; Ucgul, M. Development and field evaluation of a high-speed no-till seeding system. Soil Tillage Res. 2019, 194, 1-11. [CrossRef]

3. Shi, Y.; Xin, S.; Wang, X.; Hu, Z.; Newman, D.; Ding, W. Numerical simulation and field tests of minimum-tillage planter with straw smashing and strip laying based on EDEM software. Comput. Electron. Agric. 2019, 166, 1-9. [CrossRef]

4. $\mathrm{Gu}, \mathrm{F} . ; \mathrm{Hu}, \mathrm{Z}$;; Chen, Y.; Wu, F. Development and experiment of peanut no-till planter under full wheat straw mulching based on "clean area planting". Trans. CSAE 2016, 32, 15-23.

5. Gu, F.W.; Gao, X.M.; Wu, F.; Hu, Z.C.; Chen, Y.Q.; Zhang, C. Improvement of uniform scattering device for straw-smashing, back-throwing, no-tillage planter under complete straw mulching condition. Int. J. Agric. Biol. Eng. 2018, 11, 49-57.

6. Zhao, J.; Wang, X.; Zhuang, J.; Liu, H.; Wang, Y.; Yu, Y. Coupled Bionic Design Based on Primnoa Mouthpart to Improve the Performance of a Straw Returning Machine. Agriculture 2021, 11, 775. [CrossRef]

7. Li, A.; Fan, X.; Wu, C.; Li, H. Situation and Development Trends of Conservation Tillage in the World. Trans. CSAM 2006, 37, 177-180.

8. Liu, X.; Wang, J. Brief analysis on the development status and existing problems of no-tillage planter. Agric. Technol. 2014, 6, 203-204.

9. Shinners, K.J.; Koegel, R.G.; Pritzl, P.J. An upward cutting cut-and-throw forage harvester to reduce machine energy requirements. Trans. ASAE 1991, 34, 2287-2290. [CrossRef]

10. Shinners, K.J.; Stelzle, M.; Koegel, R.G. Improving the throwing effectiveness of an upward cutting cut-and-throw forage harvester. Trans. ASAE 1994, 37, 1059-1067. [CrossRef]

11. Chattopadhyay, P.S.; Pandey, K.P. PM-Power and Machinery: Influence of Knife Configuration and tip speed on conveyance in flail forage harvesting. J. Agric. Eng. Res. 2001, 78, 245-252. [CrossRef]

12. Jia, H.; Ma, C.; Wang, Z.; Chen, Z. Chopping and Throwing Mechanism of Corn Straw. Trans. CSAM 2003, 34, 96-99.

13. Zhai, Z.; Wang, C. Numerical simulation and optimization for air flow in an impeller blower. Trans. CSAM 2008, $39,84-87$.

14. Zhai, Z.; Wang, C.; Yang, Z. Simulation of the Movement of Air Flow and Optimization of the Parameters of an Impeller Blower. Mech. Sci. Technol. Aerosp. Eng. 2010, 29, 1352-1356.

15. Zhai, Z.; Wu, Y.; Wang, C. Dynamic simulation and high-speed camera analysis on materials moving along throwing impellers. Trans. CSAM 2012, 28, 23-28.

16. Kennedy, J.; Eberhart, R.C. Particle Swarm Optimization. In Proceedings of the ICNN'95-International Conference on Neural Networks, Perth, Australia, 27 November-1 December 1995; pp. 1942-1948.

17. Huang, W.; Xu, J.; Zhu, D.-Y.; Wu, Y.-L.; Lu, J.-W.; Lu, K.-L. Semi-active Vibration Control Using a Magneto Rheological (MR) Damper with Particle Swarm Optimization. Arab. J. Sci. Eng. 2015, 40, 747-762. [CrossRef]

18. Shi, Z.; Chen, Q. Multi-objective optimization algorithm based on quantum-behaved particle swarm and adaptive grid. Inf. Control 2011, 38, 945-951. 
19. Wei, Y.; Nu, W.; Fengwei, G.; Dezhi, L.; Xinxing, Z. Parameter optimization and experiment for the power consumption of impeller-blower. J. China Agric. Univ. 2017, 22, 99-106.

20. Omkar, S.N.; Khandelwal, R.; Ananth TV, S.; Naik, G.N.; Gopalakrishnan, S. Quantum behaved particle swarm optimization (QPSO) for multi-objective design optimization of composite structures. Expert Syst. Appl. Int. J. 2009, 36, 11312-11322. [CrossRef]

21. Shi, Y.; Eberhart, R.C. Parameter Selection in Particle Swarm Optimization; Springer: New York, NY, USA, 1998 ; pp. 591-600.

22. Wenfeng, L.; Wei, H. Optimization of polysaccharides extraction from Flammulina velutipes by box-behnken design and response surface methodology. J. Nanjing Tech Univ. 2016, 38, 95-100.

23. Montgomery, D.C. Experimental Design and Analysis, 3rd ed.; China Statistics Press: Beijing, China, 2009.

24. Cheng, G.R.; Wang, S.J.; Zou, Y.; Zhang, L. Optimization of the dacarbazine liposones preparation with Box-Behnken central composite design. J. Chang. Univ. Technol. Nat. Sci. Ed. 2011, 32, 348-353.

25. Wu, F.; Xu, H.; Gu, F.; Chen, Y.; Shi, L.; Hu, Z. Improvement of straw transport device for straw-smashing back-throwing type multi-function no-tillage planter. Trans. CSAE 2017, 33, 18-26.

26. Zhai, Z.; Gao, B.; Yang, Z.; Wu, Y. Power consumption and parameter optimization of stalk impeller blowers. Trans. CSAE 2013, $29,26-33$.

27. Jiang, Q.; Wang, Y.; Chen, J.; Wang, J.; Wei, Z.; He, Z. Optimizing the working performance of a pollination machine for hybrid rice. Comput. Electron. Agric. 2021, 187, 1-10. [CrossRef] 